\title{
Sofrimento, distúrbios osteomoleculares e depressão no contexto de trabalho: uma abordagem psicodinâmica
}

\section{Suffering, muscolosketal disorders and depression at work context: psychodynamic approach}

\author{
Sandra Regina Ayres Rocha* \\ Centro Universitário de Brasília- UNICEUB, Brasília, Distrito Federal, Brasil
}

Ana Magnólia Mendes**

Universidade de Brasília - UNB, Brasília, Distrito Federal, Brasil

Carla Faria Morrone***

Universidade de Brasília - UNB, Brasília, Distrito Federal, Brasil

\begin{abstract}
RESUMO
Neste artigo, busca-se compreender as relações entre sofrimento psíquico, distúrbios ostemusculares e depressão, a partir do arcabouço teórico da psicodinâmica do trabalho. Propõem-se compreender o processo de acometimento de DORT, e da depressão, pela análise da dinâmica intersubjetiva existente no contexto de trabalho. Apresenta-se reflexões sobre as estratégias de enfrentamento, adotadas pelos trabalhadores, para fazer frente ao seu processo de adoecimento; pontua-se também aspectos a serem evidenciados em ações de prevenção e assistência.
\end{abstract}

Palavras-chave: trabalho, sofrimento, distúrbios osteomusculares, depressão.

\begin{abstract}
The paper has as objective to articulate theoretically the interrelations between suffering, muscolosketal disorders and depression at the work context. It privileges the approach of psychodynamic of work to interpret the interrelations. It proposes as explanation, to understand muscolosketal disorders and depression, the dynamics that it involves the pleasuresuffering existences at the work. The pleasure assumes an essential character for psychic structuring for allowing the construction of the identity. The suffering is generated at the adversities of work conditions, organization and social relationships especially it is happening when the recognition of the effort and the own pleasure as affective investment at the work is denied. It explains the process of health-illness as a result of the inherent contradictions to the production context. It contributes to show that the suffering is not something pathological and to clarify the depression as an occupational disease.
\end{abstract}

Keywords: Work, suffering, muscolosketal disorders WMSD disturbances, depression. 


\section{I ntrodução}

Publicações referentes à depressão e aos distúrbios osteomusculares, relacionados ao trabalho (DORT), permeiam a literatura especializada, revelando olhares distintos. Neste artigo, apresentamos a visão da psicodinâmica do trabalho sobre o processo de acometimento destas patologias. Corrente teórica surgida na França nos anos setenta, a psicodinâmica do trabalho consolida-se como campo de pesquisa e de intervenção no Brasil e no exterior, não apenas pelo seu aparato teórico e pelos estudos científicos, mas também, atualmente, pelas interfaces e pelos diálogos com outras abordagens teóricas. Sob o enfoque de conceitos psicanalíticos, a psicodinâmica analisa a dinâmica dos processos psíquicos mobilizados pelo trabalhador diante das organizações do trabalho e os processos de adoecimento mental dos trabalhadores em função da relação que estabelecem com o trabalho.

Há muito tempo, estudiosos salientam a relação existente entre trabalho e lesões osteomusculares. Inicialmente, uma patologia que acometia poucas categorias profissionais, sem caráter epidêmico, as lesões osteomusculares ganharam vulto com a incorporação das tecnologias de automação e dos novos modelos de gestão. Na década de 50, o Japão foi o primeiro país a sinalizar o aumento expressivo de trabalhadores acometidos por DORT, sendo seguido por muitos outros países, inclusive o Brasil (RIBEIRO, 1999; SIQUEIRA; VIEIRA; QUEIROZ; UDIHARA; ARAUJ O; 2000). Diversos autores (LIMA, 1998a; RIBEIRO, 1999; BRASIL, 2000; ROCHA; FERREIRA JR., 2000) atribuem à automação dos processos produtivos, pelo qual uma grande gama de trabalhadores passou a realizar esforços físicos leves e velozes com as mãos e os dedos em posturas físicas estáticas, colaborando assim para o incremento do número de trabalhadores acometidos por DORT. Automação associada a um modelo de produção alicerçado na intensificação do trabalho, na redução dos quadros de funcionários, no aumento da jornada de trabalho, na pressão crescente por alcance a padrões de qualidade e de produtividade, entre outras características concebidas para responder às demandas do sistema produtivo sem considerar a saúde do trabalhador.

Compreendida como um conjunto de patologias do sistema músculoesquelético que acometem principalmente as extremidades superiores de uma pessoa, ocasionando, em alguns casos, degeneração dos tecidos - Ministério da Saúde (2000) -, a DORT caracteriza-se pela ocorrência, concomitante ou não, de sintomas tais como dor, formigamento, dormência, choque, sensação de peso, fadiga precoce. A hipersolicitação de membros superiores e o desrespeito ao tempo de recuperação necessário às estruturas 
anatômicas, situações comuns aos pacientes acometidos por estas patologias, podem resultar em incapacidade laborativa temporária ou permanente.

Duas vertentes de modelos teóricos procuram aprofundar o nexo causal desta patologia. Uma, psicogênica, expressa nos estudos como os de Lucire (1986), Almeida (1995) e Faria (1998), atualmente criticada por não abordar o contexto socioeconômico e por atribuir ao trabalhador única responsabilidade pelo processo de adoecimento (LIMA, 1998a; BRASIL, 2001a), privilegia a atuação de fatores psíquicos na gênese dos DORTs. Outra, representada por concepções teórico-metodológicas distintas como psicossociologia, ergonomia e psicodinâmica do trabalho, identifica aspectos do processo produtivo que, associados, concorrem para desencadear os DORTs.

A vertente da psicossociologia estabelece relações entre os fatores psicossociais e o desenvolvimento dos sintomas osteomusculares; aprofunda o estudo do estresse como variável predominante no processo de adoecimento (CARAYON, 2000; PINHEIRO, 2002). A ergonomia, partindo da análise de situações reais do trabalho, mapeia a organização e as condições do trabalho, identificando situações de risco eliciadoras ao surgimento dos DORTs e ações preventivas (SZNELWAR; ZIDAN, 2000; LACERDA, 2001; BOSCOLO, 2001). A psicodinâmica, por sua vez, privilegia o estudo da intersubjetividade existente no contexto de trabalho (MENDES et. Al., 2010; MENDES, 2008; MENDES, 2007).

O pressuposto básico da psicodinâmica preconiza que o adoecer decorre das relações estabelecidas pelo indivíduo ou pelo coletivo do trabalho com o contexto de trabalho. Para Dejours (1998), a doença somática não deve ser concebida como decorrência exclusiva da atuação psíquica de um trabalhador. Ao rejeitar o determinismo intrapsíquico, defendido pela escola psicossomática francesa (MARTY, 1993), o autor advoga em prol da primazia do intersubjetivo, defendendo ser a crise somática fruto da relação estabelecida entre o trabalhador com o "outro", compreendido como o contexto de produção de bens e de serviços, que contempla as condições de trabalho, a organização do trabalho e as relações socioprofissionais (FERREIRA; MENDES, 2003). Para a psicodinâmica, quando a relação com o "outro" ocasiona inúmeras restrições e/ou bloqueios intersubjetivos, sem possibilidade de qualquer forma de transformação do status quo pelo trabalhador, instala-se o sofrimento psíquico, que, uma vez agravado, faz surgir o adoecimento.

Segundo Dejours (1987), a vivência de sofrimento psíquico no trabalho se materializa pelos sentimentos de indignidade, inutilidade, desqualificação e vivência depressiva. Indignidade diz respeito aos sentimentos de robotização, despersonalização, privação da inteligência. Inutilidade resulta do contato do trabalhador com uma atividade desprovida de sentido, fragmentada; e desqualificação com 
uma atividade na qual o trabalhador percebe-se subutilizado. Associados, estes sentimentos caracterizam a vivência depressiva, representação máxima do sofrimento no trabalho. Manifestada, geralmente, pela sensação de cansaço, alimenta-se da vivência de adormecimento intelectual, de anquilose mental no contexto de trabalho; representa o triunfo do condicionamento do trabalhador à lógica do sistema produtivo. Em muitas situações, por manifestar-se com uma sintomatologia branda, é confundida com desmotivação ou despreparo.

Para a psicodinâmica, o trabalhador não é vítima passiva de pressões físicas e dos fatores psicossociais presentes no contexto de trabalho. Desenvolve estratégias de mediação e de ressignificação do sofrimento, sendo capaz de reverter uma situação propícia ao adoecimento. Vive, nesta condição, um estado saudável, real, e não ideal, no qual as doenças estão estabilizadas e os sofrimentos psíquicos compensados. Entretanto, quando as alternativas de mediação do sofrimento psíquico fracassam, o caminho ao adoecimento se abre. As doenças se manifestam no corpo ou no psiquismo, sinalizando que as lutas internas ou os mecanismos de defesas se enfraqueceram.

\section{Os DORTs e a psicodinâmica do trabalho}

Dejours (2000), ao expor o modelo explicativo para desenvolvimento dos DORTs, aponta que a incidência desta patologia está associada a contextos de trabalhos qualificados por três características marcantes: (1) sedentarismo das atividades e rigidez das posturas que acarretam hipertonia estável e invariante nos membros superiores; (2) relação direta com clientes associada a dificuldade de expressão de sentimentos agressivos e a presença de sentimentos de culpa; (3) aumento das cadências, por dedicação ao trabalho ou por ameaça de demissão ou fechamento da empresa. Para o autor, o DORT costuma manifestar-se em trabalhadores submetidos a um contexto de trabalho favorável à vivência de sofrimento psíquico, ou seja, por um contexto de trabalho no qual a possibilidade de existência do pensamento reflexivo e da manifestação de sentimentos é suprimida. O movimento adotado pelos trabalhadores de autoaceleração na execução das suas atividades de trabalho agrava ainda mais a vivência de sofrimento.

A autoaceleração é considerada um mecanismo de defesa utilizado pelo trabalhador para tentar abreviar o tempo de contato com uma atividade repetitiva, monótona, desprovida de significado. Quando manifestada em um contexto de trabalho que contempla enxugamento do quadro de pessoal e aumento da sobrecarga de trabalho, deixa de ser uma escolha transitória, passando a se 
configurar em um modo operatório permanente, reforçado pelos pares, pela chefia e pelos clientes; pela cultura dominante que considera a produtividade um valor. Ironicamente, o trabalhador sente-se valorizado. Entretanto, o que está sendo reconhecido é um mecanismo de defesa que para existir prescinde de sofrimento. Um descompasso entre as reais aspirações do trabalhador e as imposições do contexto de trabalho; entre o trabalhador e o seu corpo; entre um ritmo de trabalho e os limites do corpo.

Nesta perspectiva, Lancman (2001) propõe que, se a dinâmica do reconhecimento é essencial para a construção da identidade, também o é o reconhecimento do sofrimento. Segundo o autor, o acometimento de DORT está associado à incapacidade do trabalhador de valorizar-se e de reconhecer o seu sofrimento ocasionado pelo trabalho. Em tempos de intensificação do trabalho, terceirizações e desemprego, o trabalhador não se reconhece e não respeita seus próprios limites, renunciando à luta por melhores condições de trabalho.

Derriennic, Peze, e Davezies (1997), ao analisarem o trabalho repetitivo de trabalhadores acometidos por DORTs, evidenciam que a utilização de automatismos provoca, no trabalhador, sentimentos de menos valia e de subutilização do seu potencial produtivo em decorrência da percepção de realização de um trabalho sem significado; sentimentos que resultam na vivência de sofrimento psíquico. A princípio, segundo os autores, os trabalhadores manifestam sentimentos de insatisfação, expressos, inicialmente, por sensação de fadiga, nem sempre associada a uma carga excessiva de trabalho, mas sim à inatividade ou à monotonia; insatisfação, na maioria das vezes, desconsiderada e desqualificada. Os autores evidenciam que as patologias de hipersolicitação se desenvolvem, geralmente, nas organizações nas quais os critérios de gestão se opõem à inteligência dos gestos. Associados a quadros reduzidos de pessoal e ao sentimento de medo da perda do emprego, presente na maioria dos trabalhadores, esses critérios de gestão minam a expressão da individualidade do trabalhador e qualquer forma de resistência individual e coletiva ao contexto de trabalho. Para os autores, as patologias de hipersolicitação são patologias sociais, relacionadas à acumulação flexível do capital, expressão da perversão social. Os trabalhadores, frente à necessidade de serem reconhecidos pelo sistema de produção e de vivenciarem prazer no trabalho, tentam alcançar o sucesso profissional a despeito das condições que Ihe são oferecidas para tal. Neste processo de busca, são acometidos pelas patologias de hipersolicitação. Em um processo cíclico, os trabalhadores comumente empregam como mecanismo de defesa, à situação vigente, a aceleração das cadências, não somente na tentativa de responder às pressões por produção, que reduzem as capacidades de negociação e de resistência dos trabalhadores ao 
contexto de trabalho, mas também por terem interiorizado os objetivos da produção. A busca pelo reconhecimento e pela construção da identidade leva os trabalhadores à autoaceleração, na esperança de alcançarem o almejado reconhecimento.

Paralelamente, o mecanismo da negação tem sido apontado, como mostra Dejours (1999, 2004), como um dos mecanismos de enfrentamento do sofrimento mais utilizados pelos trabalhadores nos dias de hoje. Este mecanismo exerce importante papel no acometimento dos DORTs. Se há negação do sofrimento, diminui-se a possibilidade de enfrentamento coletivo e de transformação da situação que o está gerando, configuração propícia ao adoecimento do corpo.

Martins (2002), num estudo com mulheres bancárias em processo de análise, identificou sinais de sofrimento preexistentes ao acometimento de DORTs. A utilização da autoaceleração relacionada ao entorpecimento do pensar e ao não-reconhecimento do sofrimento marcaram momentos prévios ao adoecimento.

A vivência de sofrimento psíquico, portanto, é capaz de sinalizar a presença de eliciadores ao acometimento dos DORTs. O seu não reconhecimento aniquila a possibilidade de torná-lo inteligível, por meio do espaço de discussão, e, consequentemente, de ressignificálo. Como alternativa ao processo de adoecimento, o trabalhador passa a contar, apenas, com o enfrentamento individual, muitas vezes insuficiente para fazê-lo lidar com as adversidades do trabalho, e para prevenir o seu processo de adoecimento. Muitas vezes, quando marcado pela utilização de mecanismos de defesa como a autoaceleração e a negação, o que pode levar ao acometimento dos DORTs.

\section{Dort e depressão}

Apesar de representar a segunda doença mental mais frequente nos dias de hoje, o termo depressão tem sido utilizado para descrever um estado normal de humor, um estado anormal de humor, um sintoma, uma síndrome sintomática ou mesmo um grupo específico de doenças (ROCHA, 2003). Segundo o DSM IV (1995), estados depressivos devem ser classificados na categoria transtorno de humor, categoria que contempla ainda transtornos bipolares e transtornos de humor baseados na etiologia. O transtorno depressivo maior caracteriza um estado no qual, por pelo menos duas semanas, é manifestada diminuição acentuada do interesse e do prazer e pelo menos um dos seguintes sintomas: humor depressivo, alteração do sono, do apetite e/ou do peso, agitação ou retardo psicomotor, cansaço ou falta de energia, sentimento de menos valia, culpa 
excessiva, dificuldade para pensar ou concentrar-se e ideação suicida.

Alguns estudos têm discutido a associação entre depressão e doenças físicas. Vidal (1994) defende que a depressão pode ser causada por ou ser reativa a uma doença física, pode ser primária coexistindo com a doença física, ou pode expressar-se por sintomas físicos. Ratificam a associação de doenças orgânicas com a depressão os estudos de Garcia, Tafuri, Nogueira e Carcinoni (2000), Almeida (2000), Kunzler (2000), entre outros.

A relação entre depressão e DORT também vem sendo evidenciada por diferentes autores tais como: Ribeiro (1999); Sznelwar e Zidan (2000); Gravina (2000); Sato (2001); Martins (2002); Kogh, Nuwayhid, Gordon e Gucer (2000); Rossi (2008); Rossi, Mendes, Siqueira, Araújo (2009); e Santos Jr., Mendes e Araújo (2009). Ao investigarem trabalhadores afastados e reinseridos ao trabalho, identificaram relação diretamente proporcional entre limitações físicas, tempo de afastamento e incidência de sintomas depressivos, assim como constataram que $31 \%$ dos profissionais apresentavam quadro depressivo, em decorrência, principalmente, das limitações impostas pela doença e do medo de perder o emprego, mesmo depois do afastamento.

Além destes fatores, a sintomatologia dolorosa imposta pela DORT tendo sido apontada como um precursor de quadros depressivos. Figueiró (1999) revela ser a depressão comum em pacientes com dor crônica, embora não se possa assegurar nexo causal entre elas, uma vez que a queixa de dor pode fazer parte da sintomatologia dos quadros depressivos, como ratificam Wilson, Ericsson, D'Eon, Mikail e Emery (2002) - pacientes com depressão relatam maior intensidade de dor e menor capacidade de controle de sua vida.

São vários os modelos explicativos sobre o desenvolvimento e a evolução dos quadros depressivos. Embora postulados há algum tempo, suas considerações continuam atuais e servem de base para estudos nas respectivas correntes da psicologia.

Karasu (1990), referindo-se a Freud, propõe que a depressão é resultado da reativação de conflitos inconscientes infantis vividos na fase oral do desenvolvimento psicossocial. Relaciona-se à perda real ou fantasiosa de um objeto, processo pelo qual, o ego, por identificar-se narcisicamente com o objeto, perde-se de si próprio, e o superego, não podendo agredir o objeto perdido, se volta contra o ego e o conduz à perda de autoestima. A depressão, pela abordagem freudiana, é entendida como uma reação à perda.

A visão behaviorista privilegia os padrões de interação que o sujeito estabelece com o meio ambiente. Ferster (1982) a descreve como resultado do decréscimo na frequência dos comportamentos positivamente reforçados e do aumento, concomitante, na frequência de comportamentos de fuga e de esquiva. Sua gênese caracteriza-se 
pela perda ou falta de reforçamento, pelo reforçamento diferencial a não resposta e pela longa exposição à punição (CAVALCANTE, 1997; SHINOHARA, 1998; HOLMES, 2001).

Seligman (1975) explica a depressão humana pelo modelo de desamparo. Sujeitos submetidos a estímulos incontroláveis aprendem que os eventos do meio são independentes de sua resposta. A representação cognitiva desta aprendizagem gera a constatação de que resposta e consequência são independentes, e, por isto mesmo, incontroláveis os efeitos motivacionais, cognitivos e emocionais das respostas. Diante de situações nas quais a resposta que o indivíduo emite não tem importância, ou seja, naquelas em que não há possibilidade de controle sobre a consequência, instala-se o estado de desamparo. A etiologia da depressão traduz a crença de que toda ação é inútil (CAVALCANTE, 1997; RODRIGUES, 2000; HOLMES, 2001).

Beck (1979) postula que a depressão decorre dos seguintes aspectos: a) percepção negativa de si próprio - o indivíduo tende a se ver como inadequado, incapaz e fracassado, e a atribuir às experiências desagradáveis, responsabilidade pessoal; b) expectativas negativas com respeito ao meio-ambiente - o deprimido tem a tendência a interpretar as experiências de uma forma negativista. É como se o mundo estivesse pedindo muito dele ou apresentando obstáculos insuperáveis; c) expectativas negativas em relação ao futuro - falta de esperança. Ao fazer projeções, dificuldades são antecipadas e o sofrimento parece permanecer indefinidamente; a expectativa é de fracasso (BECK,1979; LOTUFO; YACUBIAN; SCALCO; GONÇALVES, 2001).

O modelo cognitivo rejeita a visão da depressão como uma desordem afetiva, mas a enfatiza como um produto de deslizes mentais. Neste modelo, a cognição é responsável por todos os sentimentos (humor) de um indivíduo. Quando se está deprimido, os pensamentos são dominados pelo negativismo, estabelece-se a crença de que as coisas estão más, crenças que ocasionam oscilações emocionais.

Ao tentarmos estabelecer correspondência entre as abordagens descritas acima e a depressão apresentada por portadores de DORT, constatamos que, embora ofereçam informações preciosas para a compreensão deste estado de sofrimento, todas elas negligenciam a dimensão trabalho e suas repercussões na saúde dos trabalhadores, fato que ratifica conclusões de alguns autores sobre a importância de se investigar fenômenos do trabalho sob o olhar de uma teoria própria que leve em consideração suas peculiaridades (SATO; ARAÚJ O; UDIHARA; FRANCO; NICOTERA; DOUDON; SETTINE; SILVESTRE, 1993; ARAÚJ O, 1998).

Nessa direção sugerimos o valor da abordagem da psicodinâmica do trabalho para explicar a depressão vinculada ao trabalho. Dejours (1984) considera como fenômeno central de um estado depressivo 
relacionado ao trabalho o embotamento afetivo, caracterizado pelo desaparecimento do prazer em todas as dimensões da vida e pela mecanização dos comportamentos. Pela robotização dos comportamentos, o individuo minimiza o seu sofrimento, anestesia-se psiquicamente.

Como mediador do processo saúde-adoecimento, o trabalho, de um lado, constitui-se fonte de prazer por possibilitar a realização e a construção da identidade, por ser meio de estruturação psíquica dos sujeitos. Por outro lado, apresenta características promotoras de sofrimento, especialmente quando não promove o reconhecimento do trabalho realizado e a vivência do prazer ou quando impossibilita qualquer forma de investimento afetivo.

A falta de reconhecimento faz emergir conflitos entre o desejo de ser reconhecido, de ser referendado pelo outro e de ter prazer e uma realidade perversa, que se apropria desse desejo de prazer para mascarar o sofrimento e para manter o sujeito produtivo. Profissionais inseridos em contextos de trabalho, geralmente, caracterizados pela alta incidência de DORTs, parecem viver condições propícias ao embotamento afetivo e ao sofrimento psíquico. A busca pelo reconhecimento e pelo prazer, em um contexto que impõe a robotização dos comportamentos, leva o trabalhador a intensificar a utilização de mecanismos tais como o da autoaceleração e o da negação, movimento que pode refletir-se na aceleração do processo de acometimento de DORTs.

\section{Considerações finais}

A análise concomitante entre sofrimento psíquico no trabalho, acometimento de DORTs e quadros depressivos aponta importantes indicadores para a compreensão do processo saúde-adoecimento dos trabalhadores. Diversos estudos abordando um ou mais de um destes temas apontam a dinâmica presente nos contextos de trabalho, que envolve conflitos e contradições, como um dos principais eliciadores do processo de adoecimento. Para a psicodinâmica do trabalho, DORTs são uma doença do trabalho, que apresentam em sua gênese a relação do trabalhador com o contexto de trabalho, a vivência não mediata de sofrimento psíquico e o fracasso na utilização de estratégias de enfrentamento às adversidades presentes no cotidiano de trabalho. Uma doença evolutiva, que se diferencia em fases clínicas, com manifestação essencialmente dolorosa, impregnada de invisibilidade, de subjetividade, de dúvidas e de incertezas, inclusive quanto à veracidade do seu diagnóstico. Uma doença com evolução lenta, que leva o trabalhador, geralmente, a negar o seu processo de adoecimento e a vivenciar sentimentos de medo em relação a uma possível demissão ou a vivência de segregação e/ou preconceito. 
Uma doença que, em pouco tempo, torna-se fonte de tristeza, de insegurança e de discriminação; pela qual, o sentimento de vergonha, na maioria das vezes, associado ao processo do adoecimento, só é vencido com a intensificação da dor, justificativa aceitável para a queda da produtividade e para os afastamentos do trabalho, mas, que altera drasticamente o sentido de ser e de existir do trabalhador (AGUIAR, 1998; RIBEIRO, 1999; FERREIRA, 2001). Ameaçado pela morte social, o portador de DORt sente-se inativo, inválido, inadequado, com menor valia social. Seu afastamento do contexto de trabalho representa uma ruptura do seu projeto de vida, e o sofrimento, até então, inerente ao trabalho invade a esfera privada, tornando-se meio propício ao acometimento de outras patologias, principalmente, a depressão.

Intervenções nos contextos de trabalho, que busquem oferecer espaços de ressignificação do sofrimento, que levem a adoção de estratégias eficazes de enfrentamento tanto pelo trabalhador como pelo seu coletivo de trabalho, devem ser viabilizadas, principalmente, em profissões caracterizadas pela automação. Salientamos algumas intervenções bem sucedidas como grupos de apoio, dinâmica de grupo, grupos focais e clínica do trabalho. (SATO; ARAÚjO; UDIHARA; FRANCO; NICOTERA; DOUDON; SETTINE; SILVESTRE, 1993; ARAÚJO; NUNES, 1998; SZNELWAR; ZIDAN 2000; MERLO; JACQUES; HOEFEL 2001).

Esperamos, ainda, que esta articulação teórica torne possível o emergir de reflexões acerca do processo de acometimento de DORTs e de quadros depressivos pelos trabalhadores. Cientes das limitações impostas pelo recorte teórico, esperamos ter provocado questionamentos e estimulado a realização de pesquisas empíricas tais como estudo dos fatores de riscos do trabalho após a reabilitação, visando verificar as variáveis que interferem na depressão depois do afastamento por Ler/Dort; estudos qualitativos para entender o processo de adoecimento pela depressão; a clínica do trabalho, que visa a ressignificação do sofrimento e a reorganização do sistema defensivo para resistir ao adoecimento; levantamentos epidemiológico do perfil sociodemográfico dos pacientes com Ler/DORT e depressão para compreender as incidências nas diferentes categorias profissionais; e, por fim, estudos com a mesma categoria profissional comparando grupos adoecidos e não adoecidos para verificar as variáveis da organização do trabalho geradoras de sofrimento e de depressão. Estas pesquisas poderão contribuir para o avanço do conhecimento teórico sobre a temática e colaborar para se pensar as políticas públicas de saúde do trabalhador. 


\section{Referências}

AGUIAR, M. C. F. O trabalhador sem seu trabalho: um estudo sobre a identidade de trabalhadores afastados do trabalho por adoecimento profissional. 1998. 134f. Dissertação (Mestrado em Psicologia) - Universidade Federal do Espírito Santo, Vitória.

ALMEIDA, M. C. C. G. Características emocionais determinantes da LER. In: _. CODO, W.; ALMEIDA, M. C. C. G. (Orgs.). LER: Lesões por Esforços Repetitivos. Rio de Janeiro: Vozes, 1995, p. 2456.

ALMEIDA, R. M. H. S. Transtornos afetivos em pacientes com demências tipo Alzheimer. 2000. 132f. Dissertação (Mestrado) Instituto de Psicologia, Universidade de São Paulo, São Paulo.

APA, American Psychiatryc Association. Manual Diagnóstico Estatístico de transtornos mentais. 4ed. (D. Batista, trad.). Porto Alegre: Artmed, 1995.

ARAÚJO, A. V.; NUNES, R. B. Contribuição da psicologia - Relato de uma experiência de grupos de portadores de LER, 1998. In:

OLIVEIRA, C. R. (Org.). Manual prático de LER. Belo Horizonte: Health. p. 317 - 340.

ARAÚJ O, J. N. G. Psicoterapia e LER. In: ; LIMA, M. E. A. ARAÚJ O, J. N. G.; LIMA, F. P. A. (Orgs.). LER: Lesões por Esforços Repetitivos: dimensões ergomômicas e psicossociais. Belo Horizonte: Health, 1998, p. 277-299.

BECK, A.; RUSH, A. Terapia cognitiva da depressão. Porto Alegre: Artmed, 1979.

BORGES, L. H. Sociabilidade, Sofrimento psíquico e lesões por esforços repetitivos entre caixas bancários. São Paulo: Fundacentro, ministério do trabalho e do emprego, 2001.

BOSCOLO, E. F. P. LER/DORT e ações ergonômicas nas empresas: estudo de casos na indústria calçadista. 2001. 145f. Dissertação (Mestrado, Departamento de Engenharia de Produção) Universidade Federal de São Carlos, São Carlos.

BRASIL. Ministério da Saúde. Protocolo de investigação, diagnóstico, tratamento e prevenção de Lesão por Esforços Repetitivos/ Distúrbios Osteomusculares Relacionados ao trabalho. Brasília: Ministério da saúde, 2000.

BRASIL. Ministério da Saúde. Lesões por Esforços repetitivos e Distúrbios osteomusculares relacionados ao Trabalho. Série $A$, n 103. Normas e Manuais Técnicos, Brasília: Ministério da saúde, $2001 a$.

BRASIL. Ministério da Saúde. Diagnóstico, tratamento, reabilitação, prevenção e fisiopatologia das LER/ DORT. Série A. Normas e Manuais Técnicos, № 105. Brasília: Ministério da saúde, 2001b. 
CARAYON, P. Work organization and work-related musculoskeletal disorders in the service sector. SZNELWARL.; ZIDAN, L. (Orgs.). Trabalho humano com sistemas informatizados no setor de serviços. São Paulo: Plêiade, 2000, p. 197-208.

CAVALCANTE, S. N. Notas sobre o fenômeno depressão a partir de uma perspectiva analítico-comportamental. Psicologia, Ciência e Profissão, Brasília, v. 17, n. 2, p. 2-12, 1997.

DEJOURS, C. Biologia Psicanálise e Somatização. In: VOLICH, R. M.; FERRAZ, F. C.; ARANTES, M. A. A. C. (Ōrgs.). Psicossoma II - Psicossomática psicanalítica São Paulo: Casa do Psicólogo, 1998, p. 39-49.

DEJOURS, C. A loucura do trabalho: estudo de psicopatologia do trabalho. São Paulo: Cortez, 1987.

DEJ OURS, C. A banalização da injustiça social. São Paulo: FGV, 1999.

DEJOURS, C. Nouvelles formes D'organisation du travail et Lésions par Efforts Répétitifs (LER): aprocche par la psychodynamique du travail. In: humano com sistemas informatizados no setor de serviços. São Paulo: Pleiâde, 2000, p. 183-196.

DERRIENNIC, F.; PEZE, M.; DAVEZIES, P. Analyse de la souffrance dans le lésions par efforts répétitifs: épidémiologie, psychosomatique, médecine du travail. In: Conservatories Nátional des Arts et Métiérs (Org.). Acts: Colloque Internacional de Psychodinamique et Psychopathologie du travail. Tome II, 1996, p. 209-251

DRUSS, B. G.; SCHLESINGER, M.; ALLEN Jr., H. Depressive symptoms, satisfaction with health care, and 2-year work outcomes in an employes population. The American Journal of Psychiatry, v. 159, n. 5, p. 731-734, 2001.

FARIA, M. A. M. O trabalho e o processo saúde-doença. In:

VOlICH, R. M.; FERRAZ, F. C.; ARANTES, M. A. A. C. (Ögs.). Psicossoma II - Psicossomática psicanalítica. São Paulo: Casa do Psicólogo, 2003, p. 183-194.

FERREIRA, $M$. C. P. Bancários portadores de distúrbios Osteomusculares relacionados ao trabalho e identidade profissional. Estudos, v.28, n. 4, p. 749-781, 2001.

FERREIRA, M. C.; MENDES, A. M. Ergonomia da atividade \& psicodinâmica do trabalho: um diálogo interdisciplinar em construção. In: FERREIRA, M. C.; MENDES, A. M. Trabalho e Riscos de Adoecimento: O Caso dos Auditores Fiscais da Previdência Social Brasileira. Brasília: Ler, Pensar, Agir. 2003, p. 32-60.

FERSTER, C. Princípios do comportamento. São Paulo: Global Editora, 1982.

FIGUEIRÓ, J. A. B. Aspectos psicológicos e psiquiátricos da experiência dolorosa. In: _._... CARVALHO, M. M. M. J. (Orgs.).

Dor um estudo multidisciplinar. São Paulo: Summus, 1999. 
GARCIA, M. A. A.; TAFURI, M. J.; NOGUEIRA, R. C.; CARCINONI, T. M. A depressão em pacientes com câncer: uma revisão. Revista de Ciências Médicas, Brasília, v. 9, n. 2, p. 80-85, 2000.

GRAVINA, M E. R. A dor e o sofrimento psíquico no trabalho: uma análise dos aspectos psicossociais relacionados ao desenvolvimento das LER. 2000. 122f. Dissertação (mestrado Faculdade de Saúde Pública) - Universidade de São Paulo. São Paulo. HÄTER, M.; REUTER, K.; WEISSER, B; SCHRETZMANN, B; ASCHENBRENNER, A.; BENGEL, J. A descriptive study of psychiatric disorders and psychosocial burden in reabilitation patients with musculoskeletal diseases. Arch phys med rehabil, Paris, v. 83, p. 461-468, 2002.

HOLMES, D. S. Psicologia dos transtornos mentais. Porto Alegre: Artmed, 2001.

KAPLAN, H.; SADOCK, B. Compêndio de psiquiatria: ciências comportamentais - psiquiatria clínica. Porto Alegre: Artmed, 1993.

KARASU T. B. Toward a clinical model of psychotherapy for depression: Systematic comparison of three psychotherapies. American J ournal Psychiatry, v. 147, n. 2, p. 133-144, 1990.

KOGH, J. P.; NUWAYHID, I.; GORDON, J.; GUCER, P. The impact of occupational injury on injured worker and family: outcomes of upper extremity cumulative trauma disorders in Maryland workers. Amercian Journal of I ndustrial Medicine, v. 38, p. 498-506, 2000.

KUNZLER, S. E. S. Freqüência de depressão maior em pacientes soropositivos para HIV. 2000. 136f. Dissertação (Mestrado) Universidade Federal do Rio de Janeiro, Rio de J aneiro.

LACERDA, E. M. A relação entre lesões por esforços repetitivos e o trabalho bancário - estudos em uma instituição na cidade do Recife. 2001. 123f. Dissertação (Mestrado em Saúde Pública) Faculdade de Saúde Pública, Universidade Federal de Pernambuco.

LANCMAN, S. Les lésions par efforts répétitifs au Brésil, l'expression de la souffrance dans le travail et la peur du chômage. In:

Conservatories Nátional des Arts et Métiérs (Org.). Acts: Troìsième Colloque Internacional de Psychodinamique et Psychopathologie du travai: La peur et l'action dans le champ du travail. Paris: CNAM, 2001.

LIMA, M. E. A. A dimensão psicológica. In: LIMA, M. E. A.; ARAÚJ O, J. N. G.; LIMA, F. P. A. (Orgs.). LER̄: Lesões por Esforços Repetitivos: dimensões ergonômicas e psicossociais. Belo Horizonte: Health, 1998, p. 201-216.

LIMA, M. E. A. A ler no setor bancário. In: . LIMA, M. E. A.; ARAÚJ O, J. N. G.; LIMA, F. P. A. (Orgs.). LER: Lesões por Esforços Repetitivos: dimensões ergonômicas e psicossociais. Belo Horizonte: Health, 1998, p. 52-107. 
LOTUFO, N. F.; YACUBIAN, J.; SCALCO, A. Z.; GONÇALVES, L. Terapia Comportamental cognitiva dos transtornos afetivos. In: RANGÉ, B. (Orgs.). Psicoterapias Cognitivo Comportamentais - um diálogo com a psiquiatria. Porto Alegre: Artmed, 2001, p. 275-286.

LUCIRE, Y. Neurosis in the workplace. Medicine J ourrnal Australia, v. 145, n. 6, p. 357-362, 1986.

MARTINS, S. R. A histeria e os DORT's: expressões do sofrimento psíquico de uma época. 2000. 187f. (Mestrado em Psicologia Clínica) - Universidade Federal de Santa Catarina, Santa Catarina.

MARTY, P. A psicossomática do adulto. Porto Alegre: Artes Médicas, 1993.

MENDES, A. M; MERLO A. R. C.; FARIA, C. M.; FACAS P. Psicodinâmica e Clínica do Trabalho: Temas, interfaces e casos brasileiros. Curitiba: Juruá, 2010.

MENDES, A. M. Trabalho e Saúde: O Sujeito entre Emancipação e Servidão. Curitiba: Juruá, 2008.

MENDES, A. M. Psicodinâmica do Trabalho - Teoria, Método e Pesquisas. São Paulo: Casa do Psicólogo, 2007.

MENDES, A. M. Cultura Organizacional e prazer-sofrimento no trabalho: uma abordagem psicodinâmica. In: _-_... TAMAYO, Á. (Org.). Cultura e saúde nas organizações. Porto Alegre: Artmed, 2004, p. 59-76.

MENDES, A. M.; CRUZ R. M. Trabalho e saúde no contexto organizacional: algumas vicissitudes teóricas in Tamayo, Álvaro (Org.). Cultura e saúde nas organizações. Porto Alegre: Artmede, 2004, p. 39-55.

MENDES, A. M.; PAZ, V. C.; BARROS, P. C. Estratégias de enfrentamento do sofrimento no trabalho bancário. Estudos e Pesquisas em Psicologia, Rio de Janeiro, v. 3, n. 1, p. 59-72, 2003.

MERLO, A. R. C., Trabalho de Grupo com Portadores de LER/ DORT: Relato de Experiência. Psicologia: Reflexão e Crítica, Porto Alegre, v. 14, n. 1, 2001.

MIRANDA, C. F. Introdução à saúde no trabalho. São Paulo: Atheneu, 1998.

PINHEIRO, F. A. Aspectos psicossociais dos distúrbios osteomusculares relacionados ao trabalho - DORT/ LER. 2002. Dissertação (Mestrado) Instituto de Psicologia, Universidade de Brasília. Brasília.

RAMAZZINI, B. A doença dos trabalhadores. São Paulo: Fundacentro. 1998.

RIBEIRO, H. P. A violência oculta no trabalho: as lesões por esforços repetitivos. Rio de Janeiro: Fiocruz. 1999. 
ROCHA, L. E.; FERREIRA Jr, M. F. Distúrbios osteomusculares relacionados ao trabalho. In: . FERREIRA J r, M. F. Saúde no trabalho: temas básicos para o profissional que cuida da saúde dos trabalhadores. São Paulo: Roca, 2000, p. 286-319.

ROCHA, L. E.; GLIMA, D. M. R. Distúrbios Psíquicos relacionados ao trabalho. In: FERREIRA Jr, M. F. Saúde no trabalho: temas básicos para o profissional que cuida da saúde dos trabalhadores. São Paulo: Roca, 2000, p. 320-351.

ROCHA, S. R. A. "O pior é não ter mais profissão, bate uma tristeza profunda": sofrimento, distúrbios osteomusculares relacionados ao trabalho e depressão em bancários. 2003. 145f. Dissertação (Mestrado) - Universidade de Brasília, Brasília.

RODRIGUES, M. J. S. F. O diagnóstico de depressão. Psicologia USP, São Paulo, v. 11, n. 1, p. 155-187, 2000.

ROSSI, E. Z.; MENDES, A. M.; SIQUEIRA, S. M. V.; ARAÚJO, J. N. G. Sedução e Servidão em um Caso de LER/ DORT: diálogo entre a Psicodinâmica do Trabalho e a Sociologia Clínica. Revista Psicologia Política, v. 9, n. 18, p. 313-330, Julho - Dezembro, 2009.

MENDES, Ana Magnólia; ROSSI, Elisabeth Zulmira. Reabilitação e reinserção no trabalho de bancários portadores de LER/ DORT: Análise Psicodinâmica. 2008. 270 f. Tese (Doutorado em Psicologia) Universidade de Brasília, Brasília.

SANTOS, L.; J R, A. V.; MENDES, A. M.; ARAÚJ O, L. K. R. Experiência em Clínica do Trabalho com Bancários Adoecidos por LER/Dort. Revista Psicologia: Ciência e Profissão, Brasília, v. 3, p. 614-625, 2009.

SALES, E. C. Trabalho doméstico e sintomas de depressão e ansiedade. 2001. Dissertação (Mestrado em Saúde Coletiva) Instituto de Saúde Coletiva, Universidade Federal da Bahia.

SATO, L. LER: objeto e pretexto para a construção do campo trabalho e saúde. Caderno de Saúde Pública, Salvador, v. 17, n. 1, p. 145$152,2001$.

SATO, L.; ARAÚJO, M.; UDIHARA, M. L.; FRANCO, M. A. J.; NICOTERA, F. N.; DOUDON, M. T. D.; SETTINE, M. M.; SILVESTRE, M. P. Atividade em grupo com portadores de L.E.R. e achados sobre a Dimensão Psicossocial. Revista Brasileira de Saúde Ocupacional, São Paulo, v. 21, n. 79, p. 49-62, 1993.

SELIGMAN, M. Desamparo - sobre depressão desenvolvimento e morte. São Paulo: Hucitec - Edusp, 1975.

SELIGMANN-SILVA, E. Psicopatologia e psicodinâmica do trabalho. In: MENDES, R. Patologia do trabalho. São Paulo: Atheneu, 1995, p. 289-310.

SHINOHARA, H. Transtornos de Humor. In:

(Orgs.). Psicoterapia Comportamental Cognitiva dos transtornos psiquiátricos. Campinas: Editorial Psy, 1998. 
SIQUEIRA, A. R.; VIEIRA, M. A. O. G.; QUEIROZ, M. F. F.; UDIHARA, M. L.; ARAÚJO, R. C. S. S. LER: dados para compreensão do problema. In: _-_. SZNELWAR, L.; ZIDAN, L. (Orgs.). Trabalho humano com sistemas informatizados no setor de serviços. São Paulo: Plêiade, 2000, p. 183-196.

SZNELWAR, L.; ZIDAN, L. Sofrimento no trabalho: uma leitura a partir de grupos de expressão. In: SZNELWAR, L.; ZIDAN, L. (Orgs.). Trabalho humano com sistemas informatizados no setor de serviços. São Paulo: Plêiade, 2000, p. 183-196.

SZNELWAR, L.; MASSETI, M. La spiralle de la souffrance - les lésions par efforts répetitifs (etude de cas auprés de travailleurs du secteur des service). In: _._. Conservatories Nátional des Arts et Métiérs (Org.). Acts: Colloque Internacional de Psychodinamique et Psychopathologie du Travail. Paris: CNAM, Tome I, 1997, p. 265-274. VIDAL, C. E. L. Depressão e doença física. Informação psiquiátrica, v. 13, n. 1, p. S19-S22, 1994.

WEIGERT, B. J.; RODRIGUEZZ, A. A.; RADWIN, R. G.; SHERMAN, J. Neuromuscular and psychological characteristics in subjects with work-related forearam pain. American Journal of Physical Medicine and Rehabilitation, v. 78, n. 6, p. 545-51, 1999.

WILSON, K. G.; ERICSSON, M. Y.; D'EON, J. L.; MIKAIL, S. F.; EMERY, P. C. Major depression and insomnia in chronic pain. The Clinical journal of pain, Paris, v. 18, p. 77-83, 2002.

\section{Endereço para correspondência}

Sandra Regina Ayres Rocha

Campus Darcy Ribeiro, ICC Ala Sul, Sala A01/049, Brasília, DF, Brasil

Endereço eletrônico: sarocha@solar.com.br

\section{Ana Magnólia Mendes}

Campus Darcy Ribeiro, ICC Ala Sul, Sala A01/049, Brasília, DF, Brasil

Endereço eletrônico: anamag@unb.br

\section{Carla Faria Morrone}

Campus Darcy Ribeiro, ICC Ala Sul, Sala A01/049, Brasília, DF, Brasil

Endereço eletrônico: carla@katanka.com.br

Recebido em: 02/09/2010

Reformulado em: 07/02/2011

Aceito para publicação em: 10/02/2011

Acompanhamento do processo editorial: Ana Maria Lopez Calvo de Feijoo

\section{Notas}

* Mestre em Psicologia Social e do Trabalho.

**Doutorado em Psicologia; Pós-doutora em Psicologia Social e do Trabalho.

*** Mestre em Psicologia Social e do Trabalho. 